\title{
Accreta Placentation: A systematic review of Prenatal Ultrasound Imaging and Grading of Villous Invasiveness
}

\author{
Eric JAUNIAUX ${ }^{1}, M D, P h D$ \\ Sally L COLLINS ${ }^{2}$,MBBS,PhD \\ Davor JURKOVIC ${ }^{1}, \mathrm{MD}$ \\ Graham J BURTON ${ }^{3}, M D$
}

1. Department of Obstetrics and Gynaecology, University College London Hospitals and UCL Institute for Women's Health, University College London (UCL), London, UK.

2. Nuffield Department of Obstetrics \& Gynaecology, University of Oxford, and the Fetal Medicine Unit, John Radcliffe Hospital, Oxford, UK

3. The Centre for Trophoblast Research, Department of Physiology, Development and Neuroscience, University of Cambridge, Cambridge, UK.

The authors report no conflict of interest

No funding was obtained for this study.

Corresponding author: Professor Eric Jauniaux, Academic Department of Obstetrics and Gynaecology, Institute for Women's Health, University College London, 86-96 Chenies Mews, London WC1E 6HX, UK.

Telephone numbers: $+44 / 207 / 3908113$ Fax: $+44 / 207 / 3908115$

E-mail: e.jauniaux@ucl.ac.uk

Word count: 4250

Condensation: Heterogeneity in terminology and study designs on ultrasound diagnosis of placenta accreta limit the evaluation of the depth of myometrial villous invasion and management strategies

Short title: Grading of accreta placenta on ultrasound imaging 


\section{Abstract}

Objective: Determining the depth of villous invasiveness before delivery is pivotal in planning individual management of placenta accreta (PA). We have evaluate the value of the various ultrasound signs described in the literature for the diagnosis of PA and in the assessment of the depth of villous invasiveness.

Data sources: We undertook a PubMed and MEDLINE search of the relevant studies published between the first prenatal ultrasound description of PA in 1982 and 30 March 2016 using key words "placenta accreta", "placenta increta", "placenta percreta", "abnormally invasive placenta", "morbidly adherent placenta" and "placenta adhesive disorder" as related to "sonography", "ultrasound diagnosis", "prenatal diagnosis", "greyscale imaging", three-dimensional (3D) ultrasound and "colour Doppler imaging".

Study eligibility criteria: All articles which correlated prenatal ultrasound imaging with pregnancy outcome.

Study appraisal and synthesis methods: Eighty-three studies, including 30 cases reports describing 38 cases of PA and 53 series describing 1078 cases were analysed. PA was subdivided in placenta creta $(\mathrm{PC})$ to describe superficially adherent placentation and placenta increta $(\mathrm{PI})$ and percreta $(\mathrm{PP})$ to describe invasive placentation. Results: Out of 53 study series, 23 did not provide data on the depth of villous myometrial invasion on ultrasound imaging or at delivery. Detailed correlations between ultrasound findings and PA grading were found in 72 cases. A loss of clear zone $(62.1 \%)$ and the presence of bridging vessels $(71.4 \%)$ were the most common ultrasound signs found in cases of PC. In PI, a loss of clear zone (84.6\%) and subplacental hypervascularity (60\%) were the most common ultrasound signs whereas, placental lacunae (82.4\%) and subplacental hypervascularity (54.5\%) were the most 
common ultrasound signs in PP. No ultrasound sign or a combination of ultrasound signs were specific of the depth of accreta placentation.

Conclusions: The wide heterogeneity in terminology used to describe the grades of accreta placentation and differences in study design limits the evaluation of the accuracy of ultrasound imaging in the screening and diagnosis of PA. This review emphasizes the need for further prospective studies using a standardised evidencebased approach including a systematic correlation between ultrasound signs of PA and detailed clinical and pathologic examinations at delivery.

Key words: Placenta, accreta, increta, percreta, ultrasound imaging, villous myometrial invasion, accreta placentation. 


\section{Introduction}

Placenta accreta $(\mathrm{PA})$ is an iatrogenic $20^{\text {th }}$ century disorder of human placentation, which is characterized by the abnormal attachment or invasion of placental tissue to the underlying uterine musculature. ${ }^{1}$ PA may have been observed before the 20 th century ${ }^{6}$ but all epidemiologic studies have shown a direct association between the increase in caesarean delivery (CD) and the increased incidence of PA in subsequent pregnancies. ${ }^{1,3-7} \mathrm{PA}$ is not exclusively a consequence of $C D$ and much smaller surgical damage to the integrity of the uterine lining, such as following uterine curettage, manual delivery of the placenta, post-partum endometritis and previous hysteroscopic surgery, endometrial resection and uterine artery embolization, has been associated with PA in subsequent pregnancies. ${ }^{1,3-8}$ The development of PA has also been reported in women with no surgical history but presenting with uterine pathology such as bicornuate uterus, adenomyosis, submucous fibroids and myotonic dystrophy. ${ }^{1,3,4}$ These individual case reports, suggest that intra-myometrial implantation of villous tissue is not always secondary to uterine surgery and may explain the few cases rare cases of PA observed before the $20^{\text {th }}$ century.

PA was first defined in 1937 by Irving and Hertig, as the "abnormal adherence of the afterbirth in whole or in parts to the underlying uterine wall". ${ }^{2}$ The failure of the placenta to separate normally from the uterus after delivery is typically accompanied by severe postpartum haemorrhage $(\mathrm{PPH})$, and attempts to remove a PA typically provokes further major haemorrhage which is associated with increased maternal morbidity and mortality. Modern pathologists have graded PA into placenta creta (PC) or vera, placenta increta $(\mathrm{PI})$ and placenta percreta $(\mathrm{PP})$ according to the depth of 
villous invasiveness. ${ }^{3,4}$ In PC, the villi adhere to the myometrium with no intermediate decidual layers between the tip of the anchoring villi and the muscular cells but do not invade the myometrium. In $\mathrm{PI}$, the villi penetrate deeply into the myometrium up to the external layer whereas in PP, the invasive villous tissue reaches and/or penetrates through the uterine serosa. The PA spectrum can therefore be subdivided into PC for abnormally adherent placentation and PI and PP for abnormally invasive placentation. Cases of PA are also often subdivided into total, partial or focal according the amount of placental issue involved. More recently, it has been suggested that cesarean scar pregnancy CSP represents a precursor of one of the different grades of $\mathrm{PA}^{10-12}$

Several concepts have been proposed to explain the pathophysiology of PA. The oldest is based on a theoretical primary defect of the biological functions of the trophoblast, leading to excessive adherence or invasion of the myometrium. The other prevailing hypothesis is that of a secondary defect of the endometrium-myometrial interface leading to a failure of normal decidualization in the area of the uterine scar allowing trophoblastic infiltration beyond the superficial myometrium and villous development inside the myometrium. ${ }^{1,3,4}$ Although, the pathogenic mechanisms of the different types of accreta placentation, including scar pregnancies, are similar, the anatomical and clinical consequences vary widely. In placenta vera, the villi simply adhere to the superficial layer of the myometrium whereas in placenta increta and percreta the villous tissue invades into and may penetrate through the entire uterine wall thickness and reach the surrounding pelvic tissues and organs.

The worst clinical outcome arises when PA and in particular, when PI or PP is unsuspected at the time of delivery and the surgeon attempts to remove the invasive 
part of the placenta leading immediately to major haemorrhage and an increasing need for emergency hysterectomy. ${ }^{13-15}$ Prenatal diagnosis of PA has therefore become essential for the safe management of this increasingly common obstetric complication. ${ }^{16-18}$ However, recent studies from UK and USA show that PA was undiagnosed before delivery in between half ${ }^{19}$ and a third ${ }^{20}$ of the cases. Determining the depth of placental invasion is essential for planning of individual management of women diagnosed with PA.

The objective of this review is to evaluate the value of the various ultrasound signs described in the international literature for the diagnosis of PA in general and for the assessment of the depth of villous invasiveness in the uterine wall in particular.

\section{Methods}

\section{Information sources and search strategy}

We conducted a systematic review of the literature and selected relevant studies that have been published between the first prenatal ultrasound description of PA by Tabsh et $\mathrm{al}^{22}$ in 1982 and 30 March 2016. We undertook a PubMed and MEDLINE search using combinations of key words of "placenta accreta", "placenta creta", "placenta increta", placenta percreta", "abnormally invasive placenta", "morbidly adherent placenta" and "placenta adhesive disorder" as related to "sonography", "ultrasound diagnosis", "prenatal diagnosis", "grey-scale imaging", three-dimensional (3D) ultrasound and "colour Doppler imaging." We limited the search to studies published in English.

\section{Eligibility creteria}


The primary eligibility criteria were articles which correlated prenatal ultrasound imaging with pregnancy outcome. We used ultrasound signs from the standardized descriptions proposed recently by the European Working Group on Abnormally Invasive Placenta

(EW-AIP) and the AIP international expert group..$^{23,24}$ On gray-scale imaging the signs of PA are: loss of the clear zone in the myometrium under the placental bed ("clear zone"); myometrial thinning to $<1 \mathrm{~mm}$ or undetectable; intra-placental lacunae often large and irregular ("moth eaten" areas); bladder wall interruption or loss (hyperechoic line between serosa and bladder lumen); placental bulge distorting the extrauterine organs; and focal exophytic mass of placental tissue extending beyond the serosa. On colour Doppler imaging (CDI) the signs used are: uterovesical hypervascularity between the myometrium and the posterior wall of the bladder; subplacental hypervascularity (placental bed); bridging vessels across the myometrium and beyond the serosa; and lacunae feeder vessels with high velocity (turbulent) flow from the arterial vasculature of myometrium.

\section{Study selection}

The initial database search provided 338 reports of which only 129 included information on ultrasound imaging using the key words described above (Figure 1). Crossreferencing provided an additional 12 reports, making a total of 141 records. After the second selection, letters with no description of the case, case reports with inconclusive diagnosis, commentaries and reviews $(n=49)$ were excluded. A further 9 reports with no description of ultrasound features were further excluded leaving 83 reports for analysis.

The articles were separated into case reports $(n=30)^{25-55}$ and series $(n=53)^{20,56-}$

107 , and were reviewed independently. PA was subdivided in placenta creta (PC) to 
describe superficially adherent placentation and placenta increta (PI) and percreta (PP) to describe invasive placentation.

\section{Synthesis of results}

Data containing study setting, study type, characteristics of study population, definition of PA, terminology, grading, ultrasound description of placental structure were obtained for each 83 studies selected. To evaluate the relationships between the depth of villous invasiveness, ultrasound signs and clinical findings management procedures including caesarean section hysterectomy (CSHT), focal myometrial resection (FMR), uterine artery embolization (UAE), uterine artery balloon occlusion (UABO), uterine artery ligation (UAL) intrauterine balloon tamponade, methotrexate (MTX), B-Lynch suture and lesions described during pathological examination were also extracted.

The case reports data were analysed using the StatGraphic data analysis and statistical software package (Manugistics, Rockville, MD).

\section{Results}

\section{Case reports characteristics}

The case reports included 38 individual cases with prenatal ultrasound findings. There were four case reports presenting findings on 2 individual cases ${ }^{25,34,36,45}$ and one including 3 individual cases. ${ }^{46}$ The PA grading was confirmed clinically or histopathologically as PC in 13 cases, $\mathrm{PI}$ in 16 cases and PP in 9 cases.

A planned CD hysterectomy with or without UAE or UAL was performed in two $\mathrm{PC}$, nine $\mathrm{PI}$ and seven PP. ${ }^{20,22,32,35-39,41,46,48,52,53}$ In the other 20 cases a conservative management was attempted including FMR with or without suture or MTX $29,31,34,43,46,50$ 
uterine curettage ${ }^{55}$ and the placental left in situ with MTX or UAE. ${ }^{25,27,28,30,41,42,45-47,49,51}$ The conservative management was unsuccessful in 12 cases, including five PC, $6 \mathrm{PI}$ and one PP, and required a secondary hysterectomy. ${ }^{25,27,28,30,34,41,42,44,45,49,55} \mathrm{~A}$ dissection or partial resection of the bladder was required in four cases of PP. ${ }^{33,35,42,54}$ The mean gestational age at delivery was 30.6 weeks (SD: 7.5 ; range 15-39 weeks). A detailed description of the pathologic findings was available in 28 cases. In the remaining 10 cases it was not available following successful conservative management but the PA grading was described at delivery.

\section{Case reports synthesis of results}

The terminology "placenta accreta" was used by 27 authors of case reports ${ }^{25-44,46-48,50-}$ $52,54,55$, "morbidly adherent placenta" by two ${ }^{45,49}$ and "abnormal placentation" in one report. ${ }^{53}$ Two authors reporting on three cases did not describe the past surgical history. ${ }^{25,40}$ In five (14.3\%) cases there was a previous history of uterine curettage only $28,30,31,50,51$ and in seven $(20.0 \%)$ the women presented with a combined history of $\mathrm{CD}$, myomectomy and/or curettage.$^{30,32,36,39,45,46,55}$ A past obstetric history of CD was reported in 23 out of 35 remaining cases $(65.7 \%)$.

Gray-scale imaging was used by all authors. In eight cases, including two PC, five PI and one PP only gray-scale imaging signs were described $25,27,33,47,48,52,55$ whereas in the remaining 30 cases, including $11 \mathrm{PC}, 11 \mathrm{PI}$ and eight PP, both grayscale and color Doppler imaging were reported. Table 1 displays the ultrasound signs identified in the diagnosis of the 38 cases reports included in the review according to the depth of villous myometrial invasion. The mean gestational age at diagnosis was 24.3 weeks (SD: 6.8; range 13-36 weeks). A loss of clear zone (92.3\%) and bridging vessels 
$(90.9 \%)$ were the most common ultrasound signs for PC. In cases of $\mathrm{PI}$, the loss of clear zone $(87.5 \%)$ and subplacental hypervascularity $(81.8 \%)$ were the most common signs whereas for PP, placental lacunae were found in all cases $(100 \%)$ and subplacental hypervascularity was found in six cases $(75 \%)$.

\section{Series characteristics}

The 53 series included 24 prospective ${ }^{58-62,65,66,70-72,76,80,83,85,89-91,93,98,101,102,105-107}$ and 29 retrospective studies with a total of 1078 cases of PA. All series except eight, which did not report data on previous surgical history ${ }^{63,66,72,81,97,98,101,106}$, included women presenting with placenta praevia and a history of $C D$ and/or other uterine surgeries. In 21 series, including 568 cases of PA, the depth of villous invasiveness was not described. ${ }^{20,59,66-69,71,72,75,76,78,81,82,85,90,91,94,96,100,104,106 .}$ In the other 32 series, the distribution of the different categories of PA were reported, including $240 \mathrm{PC}, 112 \mathrm{PI}$ and $158 \mathrm{PP}$.

A planned CD hysterectomy, with or without UAE or UAL, was the primary management option in 44 series. In 13 series, conservative management was attempted depending on the degree of myometrial invasion with secondary hysterectomy in cases of failure $20,56,62,63,71,73,75,80,84,87,92,95,97$ and in one series conservative management was successful in all cases. ${ }^{99}$ In seven series, no information was available on the outcome and management. ${ }^{20,65,85,91,98,100,107}$ Overall, a CD hysterectomy was performed in 597 out of $806(74.1 \%)$ for which the data were available. The mean gestational age range at delivery was 34-37 weeks. A detailed description of the pathologic findings was available in 29 series. In 11 series, the pathologic examination was reported as performed but no data were 
provided $^{58,59,65,67,69,81,82,87,100,104,106}$ and in 12 series there was no histopathologic information..$^{20,56,68,75,85,90,91,95,96,98,99,103}$

\section{Series synthesis of results}

The terminology used to describe PA was diverse. Seven studies used the term "morbidly adherent placenta"66,86,89,97,100,103,106, two used "placental adhesive disorders" "70,101, two used "abnormally invasive placentation" 92,104, two used "abnormally adherent placenta" or "abnormal placental adherence" ${ }^{\text {"79,83 }}$, one use "advanced invasive placentation"96 and one used the term "abnormal myometrial invasion". ${ }^{61}$

Gray-scale ultrasound was used, and the corresponding data presented by all authors except one. ${ }^{104}$ In ten series, gray-scale imaging only was used ${ }^{56-}$ $58,64,65,75,84,89,90,103$, in one series sequential two- dimensional (2D) and three-dimensional (3D) ultrasound were used..$^{77}$ In the remaining 41 series, data from both 2D grey-scale ultrasound and CDI were available. The gestational mean range at diagnosis in 31 series for which the information was available was $20-34$ weeks. Table 2 displays the ultrasound signs used by authors to diagnosed PA in the 53 series. The most commonly used signs were loss of clear zone (98\%) and placental lacunae (96.1) for grey-scale imaging and subplacental hypervascularity (85.7\%) and bridging vessels $(61.9 \%)$ for CDI. The authors of eight series provided detailed data on 2D ultrasound examination and placental grading ${ }^{65,79,84,89,95,98,102,107}$ The corresponding data are presented in Table 3. The presence of placental lacunae $(78.9 \%)$ and subplacental hypervascularity $(36.7 \%)$ were the most common ultrasound signs found. In three of these series ${ }^{65,84,102}$ the authors provided details of the placental grading for each individual standard ultrasound sign. These data were combined with those from the cases reports (Table 4) 
raising the number of cases available for analysis to 72 . This analysis confirmed that a loss of clear zone $(62.1 \%)$ and the presence of bridging vessels $(71.4 \%)$ were the most common ultrasound signs found in cases of PC, that a loss of clear zone $(84.6 \%)$ and subplacental hypervascularity $(60 \%)$ were the most common sings in PI whereas placental lacunae $(82.4 \%)$ and subplacental hypervascularity $(54.5 \%)$ were the most common signs for PP. There were no ultrasound sign or combination of ultrasound signs were specific of the depth of accreta placentation. No series reported on the lateral extension of the accreta placentation and in particular on the involvement of the cervix.

\section{Comments}

\section{Main findings}

Although some ultrasound signs are more often associated with PA, no ultrasound sign or combination of ultrasound signs are specific of the depth of accreta placentation. The wide heterogeneity in terminology and study designs in the published reports on the prenatal ultrasound diagnosis of PA could explain the low detection rate during routine ultrasound examination.

\section{Comparison with existing literature}

The origin and first use of the terminology "placenta accreta" is unknown. Langhans ${ }^{108}$ and Hart ${ }^{109}$, who first described the histology of PA, also used the term "adherent placenta". On the basis that the depth of the villous penetration of the myometrium is rarely uniform, Luke et al, suggested the name "adherent or invasive placenta" instead 
of $\mathrm{PA}^{21}$ and the first author to use to term "placenta accreta" was Baisch in $1907 .{ }^{110} \mathrm{Up}$ to the 1920s, most authors used the term "adherent placenta", whereas after that and until the present review most authors used placenta "accreta" or "increta" whereas the term "percreta" was only used regularly to describe case reports from the 1950s onwards. ${ }^{111}$ By contrast, the term "morbidly adherent placenta" dates back to the $19^{\text {th }}$ century to describe placental retention ${ }^{112}$, and has been very rarely used to describe PA until recently. Our review finds that this terminology has been increasingly used over the last decade, by authors of case reports and series of prenatal ultrasound diagnosis of PA to describe both abnormally adherent and invasive placentas. ${ }^{45,49,66,86,89,97,100,103,106}$ This terminology is inaccurate and misleading and for our analysis of the literature we have used the standard anatomical definition i.e. creta, increta \& percreta which describes accurately the depth spectrum of villous myometrial invasion.

Only one of the 20 cases personally treated by Irving and Hertig occurred after a previous CD. ${ }^{9}$ Similarly, in their review of 86 cases reports up to 1935 , only one was found after a CD. Predisposing factors at the time were a previous manual delivery and/or "vigorous" uterine curettage. Three decades later, CD was found in the history of around half of the women presenting with $\mathrm{PC}$ or $\mathrm{PI}$ in subsequent pregnancy. ${ }^{21}$ In the present review and in population studies, a history of one or more CD is reported as the main predisposing factor in more than $90 \%$ of the cases of PA. ${ }^{5-7,13,14}$ The risks of both placenta praevia and PA in subsequent pregnancies increase with the number of previous $\mathrm{CD}^{7,13,114}$ and is higher in women with a previous classical $C D .{ }^{115}$ Among women with placenta praevia, $40 \%$ of those with two previous CD and $61 \%$ of those with three previous CD develop a PA. ${ }^{7}$ This risk is independent of other maternal 
characteristics, such as parity, body mass index, tobacco use, and coexisting hypertension or diabetes. Although PA only complicates about $5 \%$ of pregnancies with placenta praevia ${ }^{13}$, and around $0.5 \%$ of women undergoing their second or third $C D^{114}$, the identification during the second trimester of a placenta praevia on ultrasound examination in a woman with a history of CD should prompt a more detailed search for signs of PA and evaluation of the depth of villous myometrial invasion.

The first antenatal grey-scale imaging descriptions of PA were reported 25 years ago by Tabsh et $a^{22}$ and ultrasonography is now the most commonly used modality for diagnosing PA. The first ultrasound sign described was the "loss of the hypoechoic retroplacental (clear) zone" found to represent an abnormal extension of the placental villi through the decidua basalis into the myometrium..$^{25,56}$ This probably corresponds the placental basal plate or utero-placental plate described by placental anatomists. ${ }^{3,4} \mathrm{In}$ 1992, Finberg and Williams ${ }^{58}$ using higher resolution grey-scale imaging identified further signs including marked thinning or absence of the myometrial zone; thinning, irregularity, or focal disruption of the utero-placental bladder zone; intraplacental vascular lacunae and presence of focal mass-like elevations or extension of placental echogenicity (exophytic) beyond the uterine serosa. The advent of CDI enabled access to visualization of the utero-placental circulation, and indicated that most cases of PA are associated with hypervascularisation patterns within the placenta and below the placental bed or subplacental zone.${ }^{25}$ Our review indicates that these signs have been commonly used since their first description and that the loss of clear zone, the presence of placental lacunae and hypervascularity of the subplacental zone were the most frequently found ultrasound signs in PA (Table 3). When analyzed for the depth of 
villous myometrial invasion, a loss of clear zone was the most common grey-scale imaging sign found for $\mathrm{PC}$ and $\mathrm{PI}$ and the presence of placental lacunae for PP. On $\mathrm{CDI}$, bridging vessels are more commonly reported in $\mathrm{PC}$, whereas subplacental hypervascularity was the most common sign found in PI and PP (Table 4). Although placental lacunae were reported in all case reports of PP (Table 1), we found that no ultrasound sign or combination of ultrasound signs were specific of the depth of accreta placentation. This can be explained by the absence of standardised description of ultrasound signs in previous studies, the high proportion of retrospective studies and the lack of PA grading confirmed by histopathology in many series.

There is increasing evidence that multidisciplinary management of patients with suspected PA is superior to standard obstetric care ${ }^{16-18,116-119}$ For such care to be organized, the diagnosis must be made prenatally. We found that most authors of series published in the last decade have used both the gray-scale and CDI ultrasound signs to evaluate retrospectively or prospectively the sensitivity of ultrasound in the prenatal diagnosis of PA. A recent systematic review and meta-analysis by D'Antonio et al ${ }^{120}$ of 23 of these studies involving 3707 pregnancies at risk of PA found that the overall performance of ultrasound is excellent (sensitivity $90.7 \%$; specificity $96.9 \%$ ), and that CDI has the best predictive accuracy. However, these studies may overestimate accuracy because they were conducted in centers specialized in prenatal diagnostics, and the number of cases of PA diagnosed prenatally were small. Out of the 22 series from D'Antonio et al review that were also included in the present review, eight did not present with information on the depth of villous invasion ${ }^{58,59,62,67,71,72,81,82}$ and one did not present any histopathologic data at all. ${ }^{85}$ This suggests that many imaging specialty 
centers may not have access to specialist perinatal pathology. Overall, only three of the series included in our review provided with a full correlation between standard 2D ultrasound signs and PA grading, and were included in Table $4 .{ }^{65,84,102}$ More prospective studies with detailed evaluation of the depth of accreta placentation at delivery are needed to better evaluate the accuracy of these ultrasound signs not only in screening for PA, but also in differentiating between the different levels of depth of myometrial invasion.

Around $75 \%$ of women with PA included in the present review were managed with planned CD hysterectomy. However, in more than half of these cases, the depth of villous invasiveness was not described. In those series in which all ${ }^{99}$, or a high proportion $^{75,80,87,95}$ of cases were successfully treated conservatively without the need for a secondary hysterectomy, it cannot be established if the corresponding PA cases were mainly superficially adherent to the myometrium or truly invasive. Ideally, the standard of reference for the different grading of PA is confirmation of the final histology after hysterectomy has been performed. The quality of the pathological examination is essential to provide feedback on the accuracy of the prenatal diagnosis of PA. A standardized method for gross and microscopic pathological examination of hysterectomy specimens with PA has recently been proposed ${ }^{121}$, and likewise the standardized ultrasound descriptions of abnormally invasive placenta ${ }^{22,24}$ should be used in the study design of further studies. Hysterectomy is not always clinically required as the bleeding can be avoided or controlled using conservative methods. In cases where a final histopathology examination is not available, the diagnosis can be based on detailed clinical information provided at the time of delivery. In women with 
severe PP, where there is deep invasion of the adjacent organs or structures, the clinical diagnosis is usually straightforward. By contrast, the differential diagnosis between PC and focal PI can be more difficult, in particular in the absence of pathological examination. The differential diagnosis between a difficult placental manual removal and an abnormally adherent placenta is also difficult in the absence of histopathological confirmation. In their classical study, Irving and Hertig highlighted this issue, and stated that "placenta accreta is not to be confused with simple retention of the after-birth either through failure of the normal mechanism of separation in a healthy uterus or through its imprisonment behind an hour glass contraction". ${ }^{9}$ The used of a standardized clinical terminology and in particular the use of "creta" to define abnormally adherent PA and increta and percreta to describe abnormally invasive forms PA is essential to the precise evaluation of perinatal data.

Histopathologically, PA is now universally defined by a partial or complete absence of decidua basalis, resulting in placental villi being attached to or invading the scarred myometrium underneath. ${ }^{1,3,4}$ Luke et $\mathrm{al}^{21}$ argued against the classification of PA proposed by some pathologists, and the further subdivision of PA into total and partial or focal, on the basis that the histological examination in cases of abnormally adherent placenta is "often distorted by attempt at manual placental delivery and/or post-partum uterine curettage". In these cases, the utero-placental interface is inevitably damaged, impairing the histological examination and making it impossible to make the diagnosis of abnormal adherent placenta or PC and evaluate its lateral extension. Deeper invasion of the trophoblast into the myometrium and infiltration of chorionic villi into myometrial vascular spaces have recently been documented in PI and PP. ${ }^{122}$ These changes 
provoke a shift in placental blood supply from a spiral artery as found in normal placentation to a supply from larger, deeper arteries, i.e. radial or arcuate, in abnormally invasive placentas. These major transformations of the uteroplacental circulation can explain the high frequency of profound vascular alterations, such as placental blood lacunae caused by blood entering the placenta at high velocity ${ }^{89}$ and hypervascularisation patterns under the placental bed found on ultrasound in PI and PP (Table 4). These findings suggest that the more invasive the placentation the more pronounced the utero-placental vascular changes are, and confirms the value of CDI in the screening of PA and in the evaluation of the depth of villous myometrial invasion.

MRI is increasingly used for the diagnosis of PA and has been reported to be useful in assessing the depth and lateral extension of myometrial invasion, especially with posterior placentation andor in obese women. Recent systematic reviews have found that prenatal MRI is highly accurate in diagnosing disorders of invasive placentation and that ultrasound and MRI have comparable predictive accuracy. ${ }^{123,124}$ However, cost and limited access to MRI makes it impractical as a screening tool for PA and ultrasound imaging remains the primary screening tool for population-based studies.

\section{Conclusions and implications}

With the increasing numbers of $C D$ worldwide and the long-term consequences of uterine scars, accurate prenatal diagnosis is a pivotal factor in optimizing the counseling, treatment, and outcome of women presenting with PA. Determining the 
depth and extension of accreta placentation is essential in planning individual management. Ultrasound sings of PA have a rather subjective quality and may not be reproducible. The use of different ultrasound equipment used may also influence the results of ultrasound examinations. Many series published in the literature over the last three decades do not provide detailed data linking prenatal ultrasound signs and clinical and histopathological findings at delivery. In addition, the inclusion of the three grades of accreta placentation into one category has led to heterogeneous data which are difficult to interpret. This can explain the major variability in terms of prenatal diagnosis accuracy, outcome and management in specialist centres, and can also explain why antenatal detection rates remain low in recent general population studies.

Pathological studies and the data of the present review suggest that PA should be separated into abnormally adherent and abnormally invasive placental tissues as these are anatomically different entities with different clinical outcomes. The term "morbidly adherent placenta" is inaccurate and misleading and should refer only to the first degree of accreta placentation where the villi simply adhere to the myometrium. PI and PP represent the most severe degree of PA and should be referred to as abnormally invasive placentation. We therefore recommend that sonographers use the term placenta "creta" if they think placentation is superficial and invasive if they think it is deep to discriminate when they are reporting their ultrasound findings. Further prospective studies that present for each individual case standardised ultrasound signs and complete clinical and pathological data are now essential to take the prenatal screening of PA from specialist centres to the general population, and to improve the outcome of this increasingly common major obstetric complication. 


\section{REFERENCES}

1. Jauniaux E, Jurkovic D. Placenta accreta: pathogenesis of a 20th century iatrogenic uterine disease. Placenta. 2012;33:244-51.

2. Harer WB. Placenta accreta. Report of eigth cases. Am J Obstet Gynecol 1956;72:1309-14.

3. Fox H, Sebire NJ. Pathology of the placenta $3^{\text {rd }}$ edition, Saunders-Elsevier, Philadelphia, 2007.

4. Benirschke K, Burton GJ, Baergen RN. Pathology of the human placenta, $6^{\text {th }}$ edition, Springer-Verlag, Berlin, 2012.

5. Miller DA, Chollet JA, Goodwin TM. Clinical risk factors for placenta previaplacenta accreta. Am J Obstet Gynecol 1997;177:210-4.

6. Wu S, Kocherginsky M, Hibbard JU. Abnormal placentation: twenty-year analysis. Am J Obstet Gynecol 2005;192:1458-61.

7. Bowman ZS, Eller AG, Bardsley TR, Greene T, Varner MW, Silver RM. Risk Factors for Placenta Accreta: A Large Prospective Cohort. Am J Perinatol. 2014;31:799-804.

8. Kanter G, Packard L, Sit AS. Placenta accreta in a patient with a history of uterine artery embolization for postpartum hemorrhage. J Perinatol. 2013;33:4823.

9. Irving C, Hertig AT. A study of placenta accreta. Surgery, Gynecol Obstet 1937;64:178-200.

10. Timor-Tritsch IE, Monteagudo A, Cali G, Palacios-Jaraquemada JM, Maymon R, Arslan AA, Patil N, Popiolek D, Mittal KR. Cesarean scar pregnancy and early placenta accreta share common histology. Ultrasound Obstet Gynecol. 2014;43:383-95.

11. Timor-Tritsch IE, Monteagudo A, Cali G, Vintzileos A, Viscarello R, Al-Khan A, Zamudio S, Mayberry P, Cordoba MM, Dar P. Cesarean scar pregnancy is a precursor of morbidly adherent placenta. Ultrasound Obstet Gynecol. 2014;44:346-53.

12. Zosmer N, Fuller J, Shaikh H, Johns J, Ross JA. Natural history of early firsttrimester pregnancies implanted in Cesarean scars. Ultrasound Obstet Gynecol. 
2015;46:367-75.

13. Solheim KN, Esakoff TF, Little SE, Cheng YW, Sparks TN, Caughey AB. The effect of cesarean delivery rates on the future incidence of placenta previa, placenta accreta, and maternal mortality. J Matern Fetal Neonatal Med. 2011;24:1341-6.

14. Bowman ZS, Manuck TA, Eller AG, Simons M, Silver RM. Risk factors for unscheduled delivery in patients with placenta accreta. Am J Obstet Gynecol. 2014;210:e1-6.

15. Creanga AA, Bateman BT, Butwick AJ, Raleigh L, Maeda A, Kuklina E, Callaghan WM. Morbidity associated with cesarean delivery in the United States: is placenta accreta an increasingly important contributor? Am J Obstet Gynecol. 2015;213:384.e1-11.

16. Warshak CR, Ramos GA, Eskander R, Benirschke K, Saenz CC, Kelly TF, Moore TR, Resnik R. Effect of predelivery diagnosis in 99 consecutive cases of placenta accreta. Obstet Gynecol. 2010;115:65-9.

17. Weiniger CF, Einav S, Deutsch L, Ginosar Y, Ezra Y, Eid L Outcomes of prospectively-collected consecutive cases of antenatal-suspected placenta accreta. Int J Obstet Anesth. 2013;22:273-9.

18. Hall T, Wax JR, Lucas FL, Cartin A, Jones M, Pinette MG. Prenatal sonographic diagnosis of placenta accreta: Impact on maternal and neonatal outcomes. J Clin Ultrasound. 2014;42:449-55.

19. Fitzpatrick K, Sellers S, Spark P, Kurinczuk J, Brocklehurst P, Knight M. The management and outcomes of placenta accreta, increta, and percreta in the UK: a population-based descriptive study. BJOG. 2014;121:62-71.

20. Bowman ZS, Eller AG, Kennedy AM, Richards DS, Winter TC, Woodward PJ, Silver RM. Accuracy of ultrasound for the prediction of placenta accreta. Am J Obstet Gynecol. 2014;211:177.e1-7.

21. Luke RK, Sharpe JW, Greene RR. Placenta accreta: the adherent or invasive placenta. Am J Obstet Gynecol. 1966;95:660-8.

22. Tabsh KM, Brinkman CR 3rd, King W. Ultrasound diagnosis of placenta increta. J Clin Ultrasound. 1982;10:288-90. 
23. Collins SL, Ashcroft A, Braun T, Calda P, Langhoff-Ross J, Morel $O$ et al., Proposed for standardized ultrasound descriptions of abnormally invasive placenta (AIP). Ultrasound Obstet Gynecol. 2016;47:271-275.

24. Alfirevic Z, Tang A-W, Collins SL, Robson SC, Palacios-Jaraquemadas, on behalf of the Ad-hoc International AIP Expert group. Pro forma for ultrasound reporting in suspected abnormally invasive placenta (AIP); an international consensus. Ultrasound Obstet Gynecol. 2016;47:276-278.

25. Pasto ME, Kurtz AB, Rifkin MD, Cole-Beuglet C, Wapner RJ, Goldberg BB. Ultrasonographic findings in placenta increta. J Ultrasound Med. 1983;2:155-9.

26. Chou MM, Ho ES, Lu F, Lee YH. Prenatal diagnosis of placenta previa/accreta with color Doppler ultrasound. Ultrasound Obstet Gynecol. 1992;2:293-6.

27. McCool RA, Bombard AT, Bartholomew DA, Calhoun BC. Unexplained positive/elevated maternal serum alpha-fetoprotein associated with placenta increta. A case report. J Reprod Med. 1992;37:826-8.

28. Rosemond RL, Kepple DM. Transvaginal color Doppler sonography in the prenatal diagnosis of placenta accreta. Obstet Gynecol. 1992;80:508-10.

29. Bromley B, Pitcher BL, Klapholz H, Lichter E, Benacerraf BR. Sonographic appearance of uterine scar dehiscence. Int J Gynaecol Obstet. 1995;51:53-6.

30. Wheeler TC, Anderson TL, Kelly J, Boehm FH. Placenta previa increta diagnosed at 18 weeks' gestation. Report of a case with sonographic and pathologic correlation. J Reprod Med. 1996;41:198-200.

31. Jauniaux E, Toplis PJ, Nicolaides KH. Sonographic diagnosis of a non-previa placenta accreta. Ultrasound Obstet Gynecol. 1996;7:58-60.

32. Chou MM, Ho ES. Prenatal diagnosis of placenta previa accreta with power amplitude ultrasonic angiography. Am J Obstet Gynecol. 1997;177:1523-5.

33. Leaphart WL, Schapiro H, Broome J, Welander CE, Bernstein IM. Placenta previa percreta with bladder invasion. Obstet Gynecol. 1997;89:834-5.

34. Kirkinen P, Helin-Martikainen HL, Vanninen R, Partanen K. Placenta accreta: imaging by gray-scale and contrast-enhanced color Doppler sonography and magnetic resonance imaging. J Clin Ultrasound. 1998;26:90-4.

35. Kim H, Hill MC, Winick AB, Shen T. Prenatal diagnosis of placenta accreta with 
pathologic correlation. Radiographics. 1998;18:237-42.

36. Maldjian C, Adam R, Pelosi M, Pelosi M 3rd, Rudelli RD, Maldjian J. MRI appearance of placenta percreta and placenta accreta. Magn Reson Imaging. 1999;17:965-71.

37. Ito T, Katagiri C, Ikeno S, Takahashi H, Nagata N, Terakawa N. Placenta previa increta penetrating the entire thickness of the uterine myometrium: ultrasonographic and magnetic resonance imaging findings. J Obstet Gynaecol Res. 1999;25:303-7.

38. Megier P, Harmas A, Mesnard L, Esperandieu OL, Desroches A. Picture of the month. Antenatal diagnosis of placenta percreta using gray-scale ultrasonography, color and pulsed Doppler imaging. Ultrasound Obstet Gynecol. 2000;15:268.

39. Chou MM, Tseng JJ, Hwang JI, Ho ES, Lee YH. Sonographic appearance of tornado blood flow in placenta previa accreta/increta. Ultrasound Obstet Gynecol. 2001;17:362-3.

40. Shih JC, Cheng WF, Shyu MK, Lee CN, Hsieh FJ. Power Doppler evidence of placenta accreta appearing in the first trimester. Ultrasound Obstet Gynecol. 2002;19:623-5.

41. Taipale $P$, Orden MR, Berg M, Manninen $H$, Alafuzoff I. Prenatal diagnosis of placenta accreta and percreta with ultrasonography, color Doppler, and magnetic resonance imaging. Obstet Gynecol. 2004;104:537-40.

42. Luo G, Perni SC, Jean-Pierre C, Baergen RN, Predanic M. Failure of conservative management of placenta previa-percreta. J Perinat Med. 2005;33:564-8.

43. Wong HS, Zuccollo J, Parker S, Burns K, Tait J, Pringle KC. Antenatal diagnosis of non-previa placenta increta with histological confirmation. Ultrasound Obstet Gynecol. 2006;27:467-9.

44. Ben Nagi J, Ofili-Yebovi D, Marsh M, Jurkovic D. First-trimester cesarean scar pregnancy evolving into placenta previa/accreta at term. J Ultrasound Med. 2005;24:1569-73.

45. Thia EW, Lee SL, Tan HK, Tan LK. Ultrasonographical features of morbidly- 
adherent placentas. Singapore Med J. 2007;48:799-802.

46. Wong HS, Zuccollo J, Tait J, Pringle K. Antenatal topographical assessment of placenta accreta with ultrasound. Aust N Z J Obstet Gynaecol. 2008;48:421-3.

47. Yee YH, Kung FT, Yu PC, Hsu TY, Cheng YF. Successful conservative management of placenta previa totalis and extensive percreta. Taiwan J Obstet Gynecol. 2008;47:431-4.

48. Wong HS, Zuccollo J, Tait J, Pringle KC. Placenta accreta in the first trimester of pregnancy: sonographic findings. J Clin Ultrasound. 2009;37:100-3.

49. Morel O, Desfeux P, Fargeaudou Y, Malartic C, Rossignol M, Perrotez C, Barranger $\mathrm{E}$. Uterine conservation despite severe sepsis in a case of placenta accreta first treated conservatively: 3-month delayed successful removal of the placenta. Fertil Steril. 2009;91:1957.e5-9.

50. Yang JI, Lee KM, Kim HY, Kim HS. "The eye of a typhoon" ultrasonograhic finding in a case of placenta previa accreta. Arch Gynecol Obstet. 2012;286:2634

51. Yarandi F, Eftekhar Z, Shojaei H, Rahimi-Sharbaf F, Baradaran F. Conservative management of placenta increta: case report and literature review. Acta Med Iran. 2011;49:396-8.

52. Pereira N, Yao R, Guilfoil DS, Richard SD, Plante LA. Placenta membranacea with placenta accreta: radiologic diagnosis and clinical implications. Prenat Diagn. 2013;33:1293-6.

53. Moretti F, Merziotis M, Ferraro ZM, Oppenheimer L, Fung Kee Fung K. The importance of a late first trimester placental sonogram in patients at risk of abnormal placentation. Case Rep Obstet Gynecol. 2014:345-348.

54. Ozyurek ES, Kahraman AA, Yildirim D, Karacaoglu UM. Clinical presentation of placenta percreta with uterine incarceration in the second trimester.J Obstet Gynaecol. 2015;35:641-3.

55. Matsuzaki S, Matsuzaki S, Ueda Y, Tanaka Y, Kakuda M, Kanagawa T, et al. A Case Report and Literature Review of Midtrimester Termination of Pregnancy Complicated by Placenta Previa and Placenta Accreta. AJP Rep. 2015;5:e6-e1. 56. Kerr de Mendonça L. Sonographic diagnosis of placenta accreta. Presentation of 
six cases. J Ultrasound Med. 1988;7:211-5.

57. Hoffman-Tretin JC, Koenigsberg M, Rabin A, Anyaegbunam A.Placenta accreta. Additional sonographic observations. J Ultrasound Med. 1992;11:29-34.

58. Finberg HJ, Williams JW. Placenta accreta: prospective sonographic diagnosis in patients with placenta previa and prior cesarean section. J Ultrasound Med. 1992;11:333-43.

59. Lerner JP, Deane S, Timor-Tritsch IE. Characterization of placenta accreta using transvaginal sonography and color Doppler imaging. Ultrasound Obstet Gynecol. 1995;5:198-201.

60. Levine D, Hulka CA, Ludmir J, Li W, Edelman RR. Placenta accreta: evaluation with color Doppler US, power Doppler US, and MR imaging. Radiology. 1997;205:773-6.

61. Twickler DM, Lucas MJ, Balis AB, Santos-Ramos R, Martin L, Malone S, et al. Color flow mapping for myometrial invasion in women with a prior cesarean delivery. J Matern Fetal Med. 2000;9:330-5.

62. Chou MM, Ho ES, Lee YH. Prenatal diagnosis of placenta previa accreta by transabdominal color Doppler ultrasound. Ultrasound Obstet Gynecol. 2000;15:28-35.

63. Chou MM, Tseng JJ, Ho ES. The application of three-dimensional color power Doppler ultrasound in the depiction of abnormal uteroplacental angioarchitecture in placenta previa percreta. Ultrasound Obstet Gynecol. 2002;19:625-7.

64. Lam G, Kuller J, McMahon M. Use of magnetic resonance imaging and ultrasound in the antenatal diagnosis of placenta accreta. J Soc Gynecol Investig. 2002;9:37-40.

65. Comstock CH, Love JJ Jr, Bronsteen RA, Lee W, Vettraino IM, Huang RR, et al. Sonographic detection of placenta accreta in the second and third trimesters of pregnancy. Am J Obstet Gynecol. 2004;190:1135-40.

66. Moodley J, Ngambu NF, Corr P. Imaging techniques to identify morbidly adherent placenta praevia: a prospective study. J Obstet Gynaecol. 2004;24:7424.

67. Warshak CR, Eskander R, Hull AD, Scioscia AL, Mattrey RF, Benirschke K, et al. 
Accuracy of ultrasonography and magnetic resonance imaging in the diagnosis of placenta accreta. Obstet Gynecol. 2006;108:573-81.

68. Sumigama S, Itakura A, Ota T, Okada M, Kotani T, Hayakawa H, et al. Placenta previa increta/percreta in Japan: a retrospective study of ultrasound findings, management and clinical course. J Obstet Gynaecol Res. 2007;33:606-11.

69. Wong HS, Cheung YK, Strand L, Carryer P, Parker S, Tait J, Pringle KC. Specific sonographic features of placenta accreta: tissue interface disruption on grayscale imaging and evidence of vessels crossing interface- disruption sites on Doppler imaging. Ultrasound Obstet Gynecol. 2007;29:239-41.

70. Masselli G, Brunelli R, Casciani E, Polettini E, Piccioni MG, Anceschi M, et al. Magnetic resonance imaging in the evaluation of placental adhesive disorders: correlation with color Doppler ultrasound. Eur Radiol. 2008;18:1292-9.

71. Japaraj RP, Mimin TS, Mukudan K. Antenatal diagnosis of placenta previa accreta in patients with previous cesarean scar. J Obstet Gynaecol Res. 2007;33:431-7.

72. Wong HS, Cheung YK, Zuccollo J, Tait J, Pringle KC. Evaluation of sonographic diagnostic criteria for placenta accreta. J Clin Ultrasound. 2008;36:551-9.

73. Dwyer BK, Belogolovkin V, Tran L, Rao A, Carroll I, Barth R, Chitkara U. Prenatal diagnosis of placenta accreta: sonography or magnetic resonance imaging? J Ultrasound Med. 2008;27:1275-81

74. Miura K, Miura S, Yamasaki K, Yoshida A, Yoshiura K, Nakayama D, et al. Increased level of cell-free placental mRNA in a subgroup of placenta previa that needs hysterectomy. Prenat Diagn. 2008;28:805-9.

75. Mazouni C, Palacios-Jaraquemada JM, Deter R, Juhan V, Gamerre M, Bretelle $F$. Differences in the management of suspected cases of placenta accreta in France and Argentina. Int J Gynaecol Obstet. 2009;107:1-3.

76. Shih JC, Palacios Jaraquemada JM, Su YN, Shyu MK, Lin CH, Lin SY, et al. Role of three-dimensional power Doppler in the antenatal diagnosis of placenta accreta: comparison with gray-scale and color Doppler techniques. Ultrasound Obstet Gynecol. 2009;33:193-203.

77. Chou MM, Chen WC, Tseng JJ, Chen YF, Yeh TT, Ho ES. Prenatal detection of 
bladder wall involvement in invasive placentation with sequential two-dimensional and adjunctive three-dimensional ultrasonography. Taiwan J Obstet Gynecol. 2009;48:38-45.

78. Warshak CR, Ramos GA, Eskander R, Benirschke K, Saenz CC, Kelly TF, et al. Effect of predelivery diagnosis in 99 consecutive cases of placenta accreta. Obstet Gynecol. 2010;115:65-9.

79. Woodring TC, Klauser CK, Bofill JA, Martin RW, Morrison JC. Prediction of placenta accreta by ultrasonography and color Doppler imaging. J Matern Fetal Neonatal Med. 2011;24:118-2.

80. El Behery MM, Rasha L E, El Alfy Y. Cell-free placental mRNA in maternal plasma to predict placental invasion in patients with placenta accreta. Int $\mathrm{J}$ Gynaecol Obstet. 2010;109:30-3.

81. Esakoff TF, Sparks TN, Kaimal AJ, Kim LH, Feldstein VA, Goldstein RB, et al. Diagnosis and morbidity of placenta accreta. Ultrasound Obstet Gynecol. 2011;37:324-7.

82. Fishman SG, Chasen ST. Risk factors for emergent preterm delivery in women with placenta previa and ultrasound findings suspicious for placenta accreta. J Perinat Med. 2011;39:693-6.

83. Hamada S, Hasegawa J, Nakamura M, Matsuoka R, Ichizuka K, Sekizawa A, et al. Ultrasonographic findings of placenta lacunae and a lack of a clear zone in cases with placenta previa and normal placenta. Prenat Diagn. 2011;31:1062-5.

84. Lim PS, Greenberg M, Edelson MI, Bell KA, Edmonds PR, Mackey AM. Utility of ultrasound and MRI in prenatal diagnosis of placenta accreta: a pilot study. Am J Roentgenol. 2011;197:1506-13.

85. Mansour SM, Elkhyat WM. Placenta previa-accreta: Do we need MR imaging. Egypt J Radiol Nuc Med. 2011;42:433-442.

86. Wong HS, Cheung YK, Williams E. Antenatal ultrasound assessment of placental/myometrial involvement in morbidly adherent placenta. Aust $\mathrm{N} \mathrm{Z} \mathrm{J}$ Obstet Gynaecol. 2012;52:67-72

87. Chantraine F, Blacher S, Berndt S, Palacios-Jaraquemada J, Sarioglu N, Nisolle $\mathrm{M}$, et al. Abnormal vascular architecture at the placental-maternal interface in 
placenta increta. Am J Obstet Gynecol. 2012;207:188.e1-9.

88. Ballas J, Pretorius D, Hull AD, Resnik R, Ramos GA. Identifying sonographic markers for placenta accreta in the first trimester. J Ultrasound Med. 2012;31:1835-41.

89. Calì G, Giambanco L, Puccio G, Forlani F. Morbidly adherent placenta: evaluation of ultrasound diagnostic criteria and differentiation of placenta accreta from percreta. Ultrasound Obstet Gynecol. 2013;41:406-12.

90. Weiniger CF, Einav S, Deutsch L, Ginosar Y, Ezra Y, Eid L. Outcomes of prospectively-collected consecutive cases of antenatal-suspected placenta accreta. Int J Obstet Anesth. 2013;22:273-9.

91. Elhawary TM, Dabees NL, Youssef MA. Diagnostic value of ultrasonography and magnetic resonance imaging in pregnant women at risk for placenta accreta. $\mathrm{J}$ Matern Fetal Neonatal Med. 2013;26:1443-9.

92. Chalubinski KM, Pils S, Klein K, Seemann R, Speiser P, Langer M, et al. Prenatal sonography can predict degree of placental invasion. Ultrasound Obstet Gynecol. 2013;42:518-24.

93. Maher MA, Abdelaziz A, Bazeed MF. Diagnostic accuracy of ultrasound and MRI in the prenatal diagnosis of placenta accreta. Acta Obstet Gynecol Scand. 2013;92:1017-22

94. Asıcıoglu O, Şahbaz A, Güngördük K, Yildirim G, Asıcıoglu BB, Ülker V. Maternal and perinatal outcomes in women with placenta praevia and accreta in teaching hospitals in Western Turkey. J Obstet Gynaecol. 2014;34:462-6.

95. Riteau AS, Tassin M, Chambon G, Le Vaillant C, de Laveaucoupet J, Quéré MP, et al. Accuracy of ultrasonography and magnetic resonance imaging in the diagnosis of placenta accreta. PLoS One. 2014;9:e94866.

96. Zhou J, Li J, Yan P, Ye YH, Peng W, Wang S, Wang XT. Maternal plasma levels of cell-free $\beta$-HCG mRNA as a prenatal diagnostic indicator of placenta accrete. Placenta. 2014;35:691-5.

97. Laban M, Ibrahim EA, Elsafty MS, Hassanin AS. Placenta accreta is associated with decreased decidual natural killer (dNK) cells population: a comparative pilot study. Eur J Obstet Gynecol Reprod Biol. 2014;181:284-8. 
98. Algebally AM, Yousef RR, Badr SS, Al Obeidly A, Szmigielski W, Al Ibrahim AA. The value of ultrasound and magnetic resonance imaging in diagnostics and prediction of morbidity in cases of placenta previa with abnormal placentation. Pol J Radiol. 2014;79:409-16.

99. Hall T, Wax JR, Lucas FL, Cartin A, Jones M, Pinette MG. Prenatal sonographic diagnosis of placenta accreta: Impact on maternal and neonatal outcomes. J Clin Ultrasound. 2014;42:449-55

100. Rac MW, Dashe JS, Wells CE, Moschos E, Mclntire DD, Twickler DM. Ultrasound predictors of placental invasion: the Placenta Accreta Index. Am J Obstet Gynecol. 2015;212:343.e1-7.

101. Pilloni E, Alemanno MG, Gaglioti P, Sciarrone A, Garofalo A, Biolcati M, et al. Accuracy of ultrasound in antenatal diagnosis of placental attachment disorders. Ultrasound Obstet Gynecol. 2016;47:302-7.

102. Satija B, Kumar S, Wadhwa L, Gupta T, Kohli S, Chandoke R, et al. Utility of ultrasound and magnetic resonance imaging in prenatal diagnosis of placenta accreta: A prospective study. Indian J Radiol Imaging. 2015;25:464-70.

103. Gilboa Y, Spira M, Mazaki-Tovi S, Schiff E, Sivan E, Achiron R. A novel sonographic scoring system for antenatal risk assessment of obstetric complications in suspected morbidly adherent placenta. J Ultrasound Med. 2015;34:561-7.

104. Collins SL, Stevenson GN, Al-Khan A, Illsley NP, Impey L, Pappas L, et al. Three-Dimensional Power Doppler Ultrasonography for Diagnosing Abnormally Invasive Placenta and Quantifying the Risk. Obstet Gynecol. 2015;126:645-53.

105. Rezk MA, Shawky M. Grey-scale and colour Doppler ultrasound versus magnetic resonance imaging for the prenatal diagnosis of placenta accreta. $\mathrm{J}$ Matern Fetal Neonatal Med. 2016;29:218-23.

106. Tovbin J, Melcer Y, Shor S, Pekar-Zlotin M, Mendlovic S, Svirsky R, et al. Predicting of morbidly adherent placenta using a scoring system: A prospective study. Ultrasound Obstet Gynecol. 2016 in press.

107. Kumar I, Verma A, Ojha R, Shukla RC, Jain M, Srivastava A. Invasive placental disorders: a prospective US and MRI comparative analysis. Acta 
Radiol. 2016 in press.

108. Langhans T. Die losung der muetterlichen eihaeute. Arch F Gynaek. 1875;8:287-97.

109. Hart DB. A contribution to the pathology symptoms and treatment of adherent placenta. Edinburgh Med J. 1889,34:816-9.

110. Baisch K. Zur pathologischen anatomie der placenta accreta. Arb Geb Pathol Anat Bact. 1907-1908;6:265-70.

111. McCarthy EJ, Nichols EO. Ruptured uterus due to placenta percreta. Am J Surg. 1950;80:485-6.

112. McDonald KN. How to prevent septicaemia in cases of morbidly adherent placenta. BMJ. 1885;1:779-80.

113. Klar M, Michels KB. Cesarean section and placental disorders in subsequent pregnancies - a meta-analysis. J Perinat Med. 2014;42:571-83.

114. Silver RM, Landon MB, Rouse DJ, Leveno KJ, Spong CY, Thom EA et al. Maternal morbidity associated with multiple repeat cesarean deliveries. Obstet Gynecol. 2006;107:1226-32.

115. Gyamfi-Bannerman C, Gilbert S, Landon MB, Spong CY, Rouse DJ, Varner MW et al. Risk of uterine rupture and placenta accreta with prior uterine surgery outside of the lower segment. Obstet Gynecol. 2012;120:1332-7.

116. Tikkanen M, Paavonen J, Loukovaara M, Stefanovic V. Antenatal diagnosis of placenta accreta leads to reduced blood loss. Acta Obstet Gynecol Scand. 2011;90:1140-6.

117. Seet EL, Kay HH, Wu S, Terplan M. Placenta accreta: depth of invasion and neonatal outcomes. J Matern Fetal Neonatal Med. 2012;25:2042-5.Kayem G, Deneux-Tharaux C, Sentilhes L; PACCRETA group. Clinical situations at high risk of placenta ACCRETA/percreta: impact of diagnostic methods and management on maternal morbidity. Acta Obstet Gynecol Scand. 2013;92:47682.

118. Chantraine F, Braun T, Gonser M, Henrich W, Tutschek B. Prenatal diagnosis of abnormally invasive placenta reduces maternal peripartum hemorrhage and morbidity. Acta Obstet Gynecol Scand. 2013;92:439-44. 
119. Silver RM, Fox KA, Barton JR, Abuhamad AZ, Simhan H, Huls CK, Belfort MA, Wright JD. Center of excellence for placenta accreta. Am J Obstet Gynecol. 2015;212:561-8.

120. D'Antonio F, lacovella C, Bhide A. Prenatal identification of invasive placentation using ultrasound: systematic review and meta-analysis. Ultrasound Obstet Gynecol. 2013;42:509-17.

121. Dannheim K, Shaiker SA, Hecht JL. Hysterectomy for placenta accreta: Methods for gross and microscopic pathology examination. Arch Gynecol Obstet. 2016;293:951-8.

122. Parra-Herran C, Djordjevic B. Histopathology of placenta creta: chorionic villi intrusion into myometrial vascular spaces and extravillous trophoblast proliferation are frequent and specific findings with implications on diagnosis and pathogenesis. Int J Gynecol Pathol. 2016. [Epub ahead of print].

123. Meng $\mathrm{X}, \mathrm{Xie} \mathrm{L}$, Song $\mathrm{W}$. Comparing the diagnostic value of ultrasound and magnetic resonance imaging for placenta accreta: a systematic review and metaanalysis. Ultrasound Med Biol. 2013;39:1958-65.

124. D'Antonio F, lacovella C, Palacios-Jaraquemada J, Bruno CH, Manzoli L, Bhide A. Prenatal identification of invasive placentation using magnetic resonance imaging: systematic review and meta-analysis. Ultrasound Obstet Gynecol. 2014;44:8-16. 
Table 1: Ultrasound signs identified in the diagnosis of 38 cases reports ranked according to the depth of villous myometrial invasion.

\section{Ultrasound signs}

Grey-scale Parameters

Loss of clear zone

Myometrial thinning

Placental lacunae

Bladder wall interruption

Placental bulge

Focal exophytic mass

CDI Parameters

Uterovesical hypervascularity

Subplacental hypervascularity

Bridging vessels

Lacunae feeder vessels

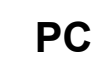

$n(\%)$
PI

$n(\%)$
PP

$n(\%)$
12(92.3) $14(87.5) \quad 5(55.6)$

$6(46.2) \quad 11(68.8) \quad 3(33.3)$

$5(38.5) \quad 9(56.3) \quad 9(100)$

$1(7.7) \quad 2(12.5) \quad 2(22.2)$

$1(12.5) \quad 1(11.1)$

1(11.1)

$(n=11) \quad(n=11) \quad(n=8)$

$\begin{array}{ccc}1(9.1) & 2(18.2) & 2(25.0) \\ 5(45.5) & 9(81.8) & 6(75.0) \\ 10(90.9) & 7(63.6) & 2(25.0) \\ 2(18.2) & 6(55.5) & 4(50.0)\end{array}$

$\mathrm{CDI}=$ Color Doppler Imaging; $\mathrm{PC}=$ placenta creta or vera; $\mathrm{PI}=$ placenta increta; $\mathrm{PP}=$ placenta percreta. 
Table 2: Distribution of the ultrasound sign used in the diagnosis of PA in 53 series.

Ultrasound signs

n (\%)

Grey-scale Parameters $(n=52)$

Loss of clear zone

$50(98.0)$

Myometrial thinning

34(66.7)

Placental lacunae

49(96.1)

Bladder wall interruption

$30(58.8)$

Placental bulge

11(22.0)

Focal exophytic mass

13(25.5)

CDI Parameters $(n=42)$

Uterovesical hypervascularity

20(47.6)

Subplacental hypervascularity

36(85.7)

Bridging vessels

26(61.9)

Lacunae feeder vessels

22(52.4)

CDI= Color Doppler Imaging 
Table 3: Distribution of standard ultrasound signs found in eight studies presenting detailed data on depth of villous myometrial invasion.

Variables

References

$\begin{array}{lllllllll}65 & 79 & 84 & 89 & 95 & 98 & 102 & 107 & \mathrm{~T}\end{array}$

$\begin{array}{lllllllll}n & n & n & n & n & n & n & n & n\end{array}$

No of cases

$15 \quad 10$

41

$26 \quad 32$

Placental grading

PC

$\begin{array}{lllllllll}8 & 8 & 5 & 15 & 16 & 16 & 3 & 1 & 72\end{array}$

PI

$\begin{array}{lllllllll}3 & 1 & 3 & 9 & -- & 12 & 4 & 2 & 34\end{array}$

PP

$\begin{array}{lllllllll}4 & 1 & 1 & 17 & 10 & 4 & 3 & 6 & 46\end{array}$

Grey-scale Parameters

Loss of clear zone

$7 \quad 10$

$4 \quad 37$

$\begin{array}{lll}23 & 20 \quad 5\end{array}$

69.7

Myometrial thinning

$\begin{array}{lll}19 & 32 & 3\end{array}$

51.0

Placental lacunae

$\begin{array}{llll}10 & 10 & 5 & 30\end{array}$

$23 \quad 28 \quad 5$

978.9

Bladder wall interruption

3

$\begin{array}{lll}15 & 16 & 1\end{array}$

23.0

Placental bulge

1

9

6.6

Focal exophytic mass

1

11

7.9

CDI Parameters $(n=128)$

Uterovesical hypervascularity

11

10

30

$\begin{array}{ll}7 & 36.7\end{array}$

Bridging vessels

12

9.3

Lacunae feeder vessels

$\begin{array}{lll}5 & 6 & 8.6\end{array}$

$\mathrm{CDI}=$ Color Doppler Imaging; ; $\mathrm{PC}=$ placenta creta or vera; $\mathrm{PI}=$ placenta increta; $\mathrm{PP}=$ placenta percreta.

References 65 and 83 included only grey-scale imaging data. 
Table 4: Ultrasound signs identified in the diagnosis of 38 cases reports and in 3 series $^{65,84,102}$ including 34 cases ranked according to the depth of villous myometrial invasion.

Ultrasound signs

$\begin{array}{ccc}\text { PC } & \text { PI } & \text { PP } \\ \mathrm{n}(\%) & \mathrm{n}(\%) & \mathrm{n}(\%)\end{array}$

Grey-scale Parameters

$(n=29) \quad(n=26) \quad(n=17)$

Loss of clear zone

18(62.1) $\quad 22(84.6) \quad 8(47.1)$

Myometrial thinning

$6(20.7) \quad 12(46.2) \quad 4(23.5)$

Placental lacunae

16(55.2) $\quad 16(61.5) \quad 14(82.4)$

Bladder wall interruption

2(6.9)

2(7.7)

$5(29.4)$

Placental bulge

1(3.9)

2(11.8)

Focal exophytic mass

$\begin{array}{ccc}- & 1(3.9) & 2(11.8) \\ - & - & 2(11.8)\end{array}$

CDI Parameters

$(n=14)$

$(n=15)$

$(n=11)$

Uterovesical hypervascularity

$3(21.4)$

2(13.3) 2(18.2)

Subplacental hypervascularity

$5(35.7)$

$9(60.0) \quad 6(54.5)$

Bridging vessels

10(71.4)

$7(46.7) \quad 2(18.2)$

Lacunae feeder vessels

$4(28.6)$

$8(53.3) \quad 5(45.5)$

$\mathrm{CDI}=$ Color Doppler Imaging; $\mathrm{PC}=$ placenta creta or vera; $\mathrm{PI}=$ placenta increta; $\mathrm{PP}=$ placenta percreta. 


\section{Figure legend}

Fig 1: Flow diagram for the selection of cases reports and series on ultrasound imaging of PA. 